\title{
Determinação de dimensões mínimas para simbologia de cartas topográficas urbanas
}

\author{
Determination of minimum dimensions for symbols of urban topographic \\ maps
}

\author{
Mônica Cristina de Castro ${ }^{1}$ \\ Claudia Robbi Sluter ${ }^{2}$
}

Recebido em março de 2019. Aprovado em junho de 2019.

\begin{abstract}
RESUMO
O objetivo deste artigo é definir critérios para o estabelecimento de dimensões mínimas para a padronização da simbologia de cartas topográficas urbanas. Este trabalho faz parte de uma de pesquisa cuja finalidade é propor e validar métodos para a produção de cartas topográficas por generalização cartográfica automatizada no Brasil. Para automatizar este processo é necessário o conhecimento de dimensões mínimas de tamanho e distância para definir e identificar problemas de representação. As cartas topográficas no Estado do Paraná são produzidas na escala 1:2.000 e, quando há necessidade, cartas em escalas menores podem ser produzidas pela redução de escala e pela seleção de feições. Como consequência, tem-se produtos cartográficos com problemas de representação. A aplicação da generalização cartográfica pode assegurar a legibilidade dessas cartas. Há uma proposta de padronização da simbologia para as cartas topográficas na escala 1.2.000, de áreas urbanas do estado do Paraná, porém não há recomendações de como abordar a simbologia quando a produção ocorre por generalização cartográfica. Para isso foi necessário desenvolver testes de percepção visual de tamanhos mínimos para símbolos coloridos condizentes com a simbologia proposta para feições de edificações, limites de propriedade e vias urbanas. Os resultados mostram que não há valores mínimos universais para tamanho e distância na cartografia topográfica, pois a percepção visual é influenciada pelas diferentes cores dos símbolos.
\end{abstract}

PALAVRAS-CHAVE: Dimensões mínimas. Cartas topográficas. Generalização cartográfica

\begin{abstract}
This paper aims to define criteria to stablish minimum dimension for symbology standardization of urban topographic maps. This work is part of a major research whose objective is to propose and validate a methodology to produce topographic maps by automated cartographic generalization in
\end{abstract}

\footnotetext{
${ }^{1}$ Programa de Pós-Graduação em Ciências Geodésicas, Universidade Federal do Paraná. Brasil. Email: castro.monicac@gmail.com

${ }^{2}$ Programa de Pós-graduação em Ciências Geodésicas, Universidade Federal do Paraná. Departamento de Geodésia da Universidade Federal do Rio Grande do Sul, Brasil. E-mail: robbisluter@gmail.com
} 
Brazil. The automation of this process requires the knowledge of minimum dimension of sizes and distances to define and identify representation problems. Paraná topographic maps of urban areas are at 1: 2,000 scale and maps at smaller scales can be produced by compilation from maps at larger scales and feature selection. Hence, there are cartographic products with representation problems. Cartographic generalization ensures that the topographic maps are legible. There is a proposal for symbology standardization for Paraná topographic mapping of urban areas, at 1:2,000 scale, but there are not recommendations for symbols when the map is produced by cartographic generalization. Therefore, it was necessary to develop visual perception tests to evaluate minimum sizes and minimum distances for colored symbols for buildings, property limits and streets features. The results indicate that minimum dimensions of size and distance are not universal values regarding topographic mapping, since visual perception is influenced by different colors of symbols.

KEYWORDS: Minimum dimensions. Topographic maps. Cartographic Generalization.

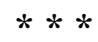

\section{Introdução}

A simbologia de cartas topográficas deve permitir a qualquer usuário uma interpretação espontânea e correta das informações representadas. Para isto, são necessárias especificações e recomendações que assegurem a legibilidade do mapa. No Brasil, há regulamentação e especificações bem definidas para a produção de cartas topográficas em escalas médias e pequenas, que são produtos do mapeamento sistemático nacional, e de responsabilidade da Diretoria de Serviço Geográfico do Exército - DSG e do Instituto Brasileiro de Geografia e Estatística - IBGE (BRASIL, 1967). O mapeamento urbano, composto por cartas topográficas em escala grande, é de responsabilidade de estados e municípios. Tal mapeamento não é normatizado. Existem trabalhos referentes a estudos e propostas de simbologia para mapeamento urbano em escala grande (TAURA, 2007; NATINGUE, 2014), assim como propostas para normatizar a simbologia cadastral (FERNANDES, 2006). Contudo, ainda há poucas pesquisas sobre mapeamento topográfico brasileiro, inclusive sobre simbologia para cartas topográficas, tanto em escala pequena quanto em escala grande. 
O mapeamento sistemático brasileiro apresenta diversos problemas, decorrentes de sua história e da História do Brasil (SLUTER et al., 2018) Entre as questões históricas, três delas têm significativa relevância: (1) a falta de pesquisa científica voltada às soluções para o mapeamento topográfico sistemático do território brasileiro e que considere, principalmente, as características de sua paisagem; (2) a consequente realização do mapeamento topográfico com métodos e técnicas importados de outros países, incluindo as normas e padrões para escalas médias e pequenas (entre 1:25.000 até 1:1.000.000); e (3) a falta de normas e de padrões para cartas topográficas em escalas grandes (SLUTER et al., 2018). Além da falta de pesquisa científicas, mesmo com a produção ocasional de cartas topográficas, nunca houve o mapeamento completo do território brasileiro nas escalas 1:25.000; 1:50.000 e 1:100.000 (CAMBOIM e SLUTER, 2009).

Cada estado e município estabelece normas para a produção, uso e gestão das cartas topográficas em grande escala de acordo com suas necessidades, pois este tipo de mapeamento não é tratado de maneira sistemática (PARANÁ, 2010). As cartas topográficas do estado do Paraná são produzidas na escala base 1:2.000. Quando há necessidade de cartas em escalas diferentes da escala base, estas são produzidas por redução geométrica de escala e pela seleção de informações, ou por novos levantamentos aerofotogramétricos. Isto se dá porque não se produz cartas topográficas com os métodos e as técnicas da generalização cartográfica para o mapeamento sistemático. O resultado são produtos cartográficos com problemas de representação e com uma elevada relação custo/benefício (TAURA, 2007; CASTRO, 2014; COMÉ, 2014; NATINGUÉ, 2014). Deste modo, há necessidade de se incluir aspectos do processo de generalização cartográfica na produção de cartas topográficos no Brasil.

O objetivo da pesquisa apresentada neste artigo é definir critérios para o estabelecimento de dimensões mínimas para a simbologia proposta por Sluter et al. (2018) para as feições representadas em cartas topográficas em escala grande. Este trabalho faz parte de um projeto de pesquisa cuja 
finalidade é propor e validar métodos para a produção de cartas topográficas por generalização cartográfica automatizada no Brasil. Para automatizar este processo é necessário dividi-lo em etapas: avaliação cartométrica e aplicação dos operadores de generalização.

A avaliação cartométrica requer o conhecimento de tamanhos mínimos para os símbolos para que seja possível definir e identificar um problema de representação (MCMASTER e SHEA, 1992). A distância entre feições e tamanho de feições são exemplos destas dimensões mínimas. Valores mínimos de tamanho e distância devem ser respeitados para manter a legibilidade. Por isso, a Sociedade Suíça de Cartografia - SSC (2002) recomenda dimensões mínimas para tamanhos de símbolos e distâncias entre símbolos, dentro dos limites de percepção visual, para símbolos pontuais, lineares e de área e não coloridos, ainda que apresente recomendações para símbolos em tons cinza claro.

No Estado do Paraná, a padronização da simbologia para mapeamento topográfico é definida por Sluter et al. (2018) e adotada pela Câmara Técnica de Cartografia e Geoprocessamento (CTCG) para a escala 1:2.000. Ela abrange a classificação das feições, suas definições e o projeto de seus símbolos. Esta simbologia inclui especificações para cores, espessuras e estilos de linhas, tamanhos para símbolos pontuais e especificações para toponímias (PARANÁ, 2009; SLUTER et al., 2018). Porém, não há indicações de valores mínimos a serem observados para a produção de cartas topográficas.

Devido à necessidade dos usuários de cartas topográficas dos municípios paranaenses, as cartas topográficas que empregam esta simbologia devem ser produzidas na escala base, 1:2.000, e em escalas menores, como 1:5.000 e 1:10.000 (NALINI, 2005). Não há recomendações de como abordar a simbologia quando o processo de produção se dá por generalização cartográfica. Taura (2007) definiu dimensões mínimas a serem observadas durante o processo de generalização para símbolos cartográficos coloridos sem preenchimento e em preto e branco. 
Valores mínimos para tamanho, área e distância entre feições não são universais na área da cartografia topográfica. Sayidov e Weibel (2016) afirmam que diferentes dimensões mínimas, baseadas nos limites de percep̧̧ão visual, são utilizadas por diferentes pesquisadores e por diferentes agências de mapeamento. No entanto, tais valores são recomendados para símbolos pretos. Para símbolos coloridos, como os empregados pela CTCG, tais valores devem ser maiores (SSC, 2002). Deste modo, para estabelecer critérios para a produção de cartas topográficas por generalização cartográfica foi necessário desenvolver avaliações de percepção visual de tamanhos mínimos para símbolos coloridos individuais condizentes com a proposta da simbologia para as convenções cartográficas da cartografia topográfica brasileira.

Neste contexto, o problema de pesquisa apresentado nesse trabalho é: as diferenças em percepção visual de diferentes cores podem influenciar a percepção de dimensões mínimas dos símbolos cartográficos?

Como hipótese afirma-se que: (1) a percepção visual é influenciada pelas diferentes cores dos símbolos; (2) para a comunicação cartográfica no processo de generalização cartográfica ser preservada e (3) para automatização da generalização cartográfica ser possível de ser realizar é necessário se conhecer os tamanhos e distâncias mínimos dos símbolos, então, é necessário se estabelecer as dimensões mínimas dos símbolos cartográficos com base nas diferenças de percepção visual das diferentes cores.

As tarefas de percepção visual desenvolvidos nesta pesquisa avaliam os símbolos das seguintes feições: edificações, vias urbanas e limites de propriedade, nas suas respectivas tipificações. As características destes símbolos incluem diversas cores para preenchimento e contorno.

A simbologia utilizada e o desenvolvimento de cada questão apresentada nas tarefas de percepção visual são apresentados no item Metodologia. As características dos participantes e a apresentação dos resultados de cada questão são abordados no item Resultados. Por fim, a 
discussão dos resultados e a indicação de sugestões para aprimoramento e continuidade da pesquisa são tratados no item Discussão e Recomendações.

\section{Metodologia}

Nesta pesquisa foram elaborados experimentos com o objetivo de avaliar a percepção visual de símbolos lineares e de áreas utilizados para representar feições de edificações, limites de propriedades e vias urbanas. Os resultados são necessários para a automatização da avaliação cartométrica realizada no processo de generalização cartográfica. Os valores utilizados nos testes incluem medidas indicadas para símbolos impressos pelas seguintes agências de mapeamento: Instituto Geográfico Nacional da Costa Rica, Instituto Nacional de Informações Geográficas e Florestais da França, Diretoria de Serviço Geográfico do Exército - DSG, Serviço Geológico dos Estados Unidos da América - USGS e pela Sociedade Suíça de Cartografia SSC. As avaliações consideraram a simbologia impressa em fundo branco e foram apresentadas em folhas A4, com símbolos de acordo as recomendações de Sluter et al. (2018).

Conforme a padronização empregada pela CTCG as edificações são representadas como símbolos de área com quatro cores diferentes (Quadro 1) relacionadas à diferentes classes: (1) edificações residenciais, hospitais, escolas, igrejas, edificações culturais e turísticas; (2) edificações industriais; (3) edificações públicas e de transporte; e (4) edificações comerciais e de serviço. As rodovias e vias urbanas são divididas em três classes e, apesar de serem caracterizadas pela dimensão espacial linear, mas são representadas pela primitiva gráfica de área, uma vez que suas larguras são representadas pela relação direta com a escala, ou seja, não podem ser consideradas como símbolo lineares. Além disso, pela sua classificação em ruas pavimentas ser definida no nível de medida nominal, são representadas com dois matizes de cores (Quadro 1). 
Devido as variadas características gráficas dos símbolos de edificações, optou-se por testar separadamente os símbolos para cada uma das diferentes cores adotadas pela padronização da CTCG (2009). Assim dividiu-se a avaliações em Tipo 1 - Feições comerciais e de serviços, Tipo 2 - Feições industriais, Tipo 3 - Feições públicas e de transporte, e Tipo 4 - Feições residenciais, igrejas, escolas etc., conforme o Quadro 1. As questões relacionadas às rodovias, às vias urbanas e aos limites de propriedade foram apresentadas em todas os testes, não havendo diferenciação de cores para essas classes de feições.

Quadro 1 - Especificações da simbologia empregada no teste de percepção visual

\begin{tabular}{|c|c|c|c|c|c|c|c|}
\hline \multirow{3}{*}{$\begin{array}{c}\text { Dimensão } \\
\text { espacial }\end{array}$} & \multirow{3}{*}{$\begin{array}{c}\text { Primitiva } \\
\text { gráfica }\end{array}$} & \multirow{3}{*}{ Feições } & \multicolumn{5}{|c|}{ Simbologia } \\
\hline & & & \multicolumn{3}{|c|}{ Contorno } & \multicolumn{2}{|c|}{ Preenchimento } \\
\hline & & & Símbolo & RGB & Espessura & Símbolo & RGB \\
\hline \multirow{4}{*}{ Área } & \multirow{4}{*}{ Área } & $\begin{array}{c}\text { Comerciais e } \\
\text { de serviços }\end{array}$ & & $255,166,0$ & $0,18 \mathrm{~mm}$ & & $255,211,127$ \\
\hline & & Industriais & & $0,0,0$ & $0,18 \mathrm{~mm}$ & & $156,156,156$ \\
\hline & & $\begin{array}{c}\text { Públicas e de } \\
\text { transporte }\end{array}$ & & $131,64,191$ & $0,18 \mathrm{~mm}$ & & $194,163,224$ \\
\hline & & $\begin{array}{l}\text { Residenciais, } \\
\text { igrejas, } \\
\text { escolares, de } \\
\text { saúde, } \\
\text { culturais e } \\
\text { turísticas }\end{array}$ & & $255,0,0$ & $0,18 \mathrm{~mm}$ & & $255,190,190$ \\
\hline \multirow{3}{*}{ Linha } & \multirow{3}{*}{ Área } & Rodovias & - & - & - & 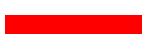 & $255,0,0$ \\
\hline & & $\begin{array}{c}\text { Ruas } \\
\text { pavimentadas }\end{array}$ & - & - & - & 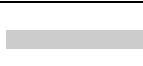 & $204,204,204$ \\
\hline & & $\begin{array}{c}\text { Ruas não } \\
\text { pavimentadas }\end{array}$ & - & - & - & Dras & $255,218,186$ \\
\hline Linha & Linha & $\begin{array}{l}\text { Limites de } \\
\text { propriedades }\end{array}$ & & $0,0,0$ & $0,18 \mathrm{~mm}$ & - & - \\
\hline
\end{tabular}

Fonte: Adaptado de Paraná (2010).

O Quadro 2 apresenta as questões do teste relacionadas a cada elemento gráfico e seus respectivos símbolos. Em cada questão havia sete alternativas de tamanhos e distâncias, e o participante deveria marcar somente as alternativas consideradas claramente legíveis. As avaliações 
foram conduzidas com base na percepção visual das dimensões mínimas, que foram definidas com base nos problemas de visibilidade e legibilidade.

Quadro 2 - Aspectos e questões apresentadas no teste de percepção visual

\begin{tabular}{|c|c|c|c|}
\hline $\begin{array}{c}\text { Primitiva } \\
\text { gráfica }\end{array}$ & Elemento gráfico & Símbolo & Questão \\
\hline Linha & Linhas paralelas & $\overline{\overline{\bar{E}}}$ & $\begin{array}{c}\text { Marque as alternativas nas quais você vê } \\
\text { claramente } 3 \text { linhas paralelas }\end{array}$ \\
\hline \multirow{6}{*}{ Área } & $\begin{array}{l}\text { Largura de um } \\
\text { retângulo sólido }\end{array}$ & & $\begin{array}{c}\text { Abaixo são apresentadas sequências de } \\
\text { polígonos. Marque as alternativas nas quais } \\
\text { você passa a ver o retângulo como uma linha. }\end{array}$ \\
\hline & $\begin{array}{l}\text { Lado de um } \\
\text { quadrado sólido }\end{array}$ & $\square$ & $\begin{array}{l}\text { Abaixo é apresentada uma sequência de } \\
\text { polígonos. Marque as alternativas nas quais } \\
\text { você vê facilmente os símbolos }\end{array}$ \\
\hline & $\begin{array}{l}\text { Lado de área } \\
\text { interna }\end{array}$ & 0 & $\begin{array}{c}\text { As figuras abaixo apresentam áreas internas. } \\
\text { Em quais alternativas você vê claramente essa } \\
\text { área e seu contorno? }\end{array}$ \\
\hline & $\begin{array}{l}\text { Detalhe na } \\
\text { representação }\end{array}$ & & $\begin{array}{l}\text { As figuras abaixo apresentam detalhes na sua } \\
\text { representação. Em quais alternativas você vê } \\
\text { claramente estes detalhes? }\end{array}$ \\
\hline & $\begin{array}{l}\text { Distância entre } \\
\text { polígonos }\end{array}$ & $\square \square \square$ & $\begin{array}{c}\text { Uma sequência de figuras de área é } \\
\text { apresentada abaixo. Marque as alternativas } \\
\text { nas quais você vê o espaçamento entre as } \\
\text { feições. }\end{array}$ \\
\hline & $\begin{array}{l}\text { Distância entre } \\
\text { polígono e linha }\end{array}$ & $\square$ & $\begin{array}{c}\text { A seguir são apresentadas sequências de } \\
\text { figuras lineares e de área. A cada sequência, } \\
\text { marque as alternativas nas quais você vê o } \\
\text { espaçamento entre as feições. }\end{array}$ \\
\hline
\end{tabular}

Fonte: Elaborado pelas autoras.

A publicação Map Graphics and Generalisation da SSC (2002) e os testes de percepção visual conduzidos por Taura (2007) na sua pesquisa de mestrado foram usados como base para a organização e desenvolvimento do teste. A SSC (2002) recomenda dimensões mínimas dos símbolos com base em 15 aspectos. Porém, algumas recomendações não se enquadram na simbologia avaliada neste trabalho, como por exemplo, símbolos pontuais, linhas pontilhadas e hachuras. Deste modo, apenas seis daquelas recomendações foram usadas como referências. Os testes de percepção visual realizados por 
Taura (2007) determinam dimensões mínimas de símbolos para 10 aspectos. No entanto, sete desses aspectos se referem às feições não avaliadas nesta pesquisa, como toponímia e símbolos pontuais.

A premissa do experimento é que os tamanhos dos símbolos em cada uma das questões são os mesmos independentemente da cor do símbolo avaliado.

\subsection{Procedimentos}

O teste foi dividido em duas partes: perguntas pessoais e tarefas de percepção visual. Perguntas pessoais incluíram questões relacionadas a idade, área de estudo e existência de problemas visuais. Estes questionamentos foram necessários para se saber até que ponto problemas visuais podem interferir na percepção visual. $\mathrm{O}$ experimento consistiu em:

a) Definir os aspectos a serem verificados com base em problemas de representação;

b) Analisar os aspectos geométricos dos símbolos das feições a serem generalizadas;

c) Definir as questões para compor o teste de percepção visual e as possibilidades de respostas (definir dimensões);

d) Produzir imagens com a simbologia definida segundo os diferentes tamanhos propostos;

e) Organizar as questões;

f) Aplicar os testes.

Nesta pesquisa foram identificados problemas de representação com as seguintes características: congestionamento de informações, proximidade entre as feições e tamanho de feições individuais. Baseado nisto, foram definidos os aspectos a serem avaliados, que podem ser caracterizados pela distância e pelo tamanho dos símbolos. 
A simbologia das feições analisadas consiste em feições lineares e feições de área (Quadro 1). Foram analisadas as características dos elementos geométricos dos símbolos (linhas, quadrados e retângulos) para definir suas características gráficas (contornos e cores). Com estas características e com o conhecimento dos aspectos a serem avaliados, foi possível definir as seis questões apresentadas no teste. Do aspecto tamanho, derivou-se três componentes: lado do quadrado, lado do detalhe de uma edificação e lado da área interna de uma edificação. $\mathrm{O}$ aspecto distância foi analisado em três perspectivas: distância entre linhas paralelas, distância entre feições de área e distância entre uma feição linear e uma feição de área.

\subsection{Questões do Teste de Percepção Visual}

O espaçamento entre linhas paralelas retas foi verificado por ser uma situação frequente nas cartas topográficas, representações de linhas de contorno das feições de quadras, e de edificações, linhas de limite de propriedade. Apenas a SSC (2002) recomenda um espaçamento mínimo entre elas. As sete opções de espaçamento apresentadas correspondem aos mesmos valores utilizados por Taura (2007): 0,10 mm;0,20 mm;0,25 mm;0,30 mm; 0,50 mm; 0,70 mm, e 1,00 mm. As linhas representadas na Figura 1 tem 1,00 $\mathrm{mm}$ de espaçamento entre si e $0,18 \mathrm{~mm}$ de espessura. Tais distâncias são independentes do comprimento das linhas paralelas.

Figura 1 - Linhas paralelas

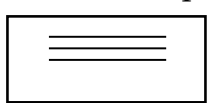

Fonte: Elaborada pelas autoras.

As rodovias e vias urbanas são representadas com símbolos de área. Porém, com a redução de escala pode ser que seja necessário representar estas feições como linhas. Neste cenário, a espessura da linha não corresponde à largura da via em escala, e é necessário definir quando uma rua deve ser 
representada com símbolo linear. Para tanto, é preciso estabelecer uma largura mínima para que uma via, representada com símbolo de área, tenha a largura da via na escala do mapa. Nesta questão os valores avaliados foram: $0,30 \mathrm{~mm} ; 0,50 \mathrm{~mm} ; 0,80 \mathrm{~mm} ; 1,0 \mathrm{~mm} ; 1,2 \mathrm{~mm} ; 1,5 \mathrm{~mm}$ e $2,00 \mathrm{~mm}$.

Ao reduzir a escala de uma carta topográfica, uma feição de área pode ser eliminada ou exagerada. Tal decisão é dependente do tamanho desta feição (MCMASTER e SHEA, 1992). Deste modo, foi necessário testar o tamanho de um polígono. Em sua maioria, as agências de mapeamento não recomendam um tamanho mínimo para feições de área, seja o lado do quadrado ou retângulo, ou mesmo área mínima. A SSC (2002), o IGN da França (REGNAULD, 2001) e o IGN da Costa Rica (COSTA RICA, 2016) apresentam os seguintes valores para lado de um quadrado: $0,80 \mathrm{~mm} ; 0,50$ $\mathrm{mm}$, e $0,30 \mathrm{~mm}$, respectivamente. Os valores utilizados neste teste foram: $0,10 \mathrm{~mm} ; 0,30 \mathrm{~mm} ; 0,50 \mathrm{~mm} ; 0,80 \mathrm{~mm} ; 1,00 \mathrm{~mm} ; 1,20 \mathrm{~mm}$ e $1,50 \mathrm{~mm}$.

Poucas edificações apresentam uma área interna. Apesar da baixa ocorrência, foi necessário testar o tamanho mínimo desta área, pois suas dimensões podem resultar em problemas de representação. Dentre os manuais de produção de cartas topográficas, apenas o manual da SSC (2002) recomenda uma dimensão mínima para este aspecto. Os valores para o lado de uma área interna avaliados foram: 0,20 mm; 0,30 mm; 0,40 mm;0,50 mm; $0,55 \mathrm{~mm} ; 0,60 \mathrm{~mm}$ e $0,65 \mathrm{~mm}$. Ressalta-se que para as figuras apresentadas no teste apenas o tamanho da área interna foi modificado, o polígono permaneceu com as seguintes medidas $5,5 \mathrm{~mm} \times 3,5 \mathrm{~mm}$.

Pode-se observar na Figura 2 como edificações com detalhes na sua representação são recorrentes. Somente a SSC (2002), IGN da França (2001) e Taura (2007) abordam este aspecto. Os valores analisados nesta questão foram: $0,15 \mathrm{~mm} ; 0,20 \mathrm{~mm} ; 0,25 \mathrm{~mm} ; 0,30 \mathrm{~mm} ; 0,50 \mathrm{~mm} ; 0,80 \mathrm{~mm}$ e $1,00 \mathrm{~mm}$. Para a avaliação deste aspecto, somente o tamanho do detalhe foi alterado, o polígono permaneceu com as seguintes medidas 5,0 mm X 3,5 mm. 
Figura 2 - Exemplos de edificações com detalhes na representação

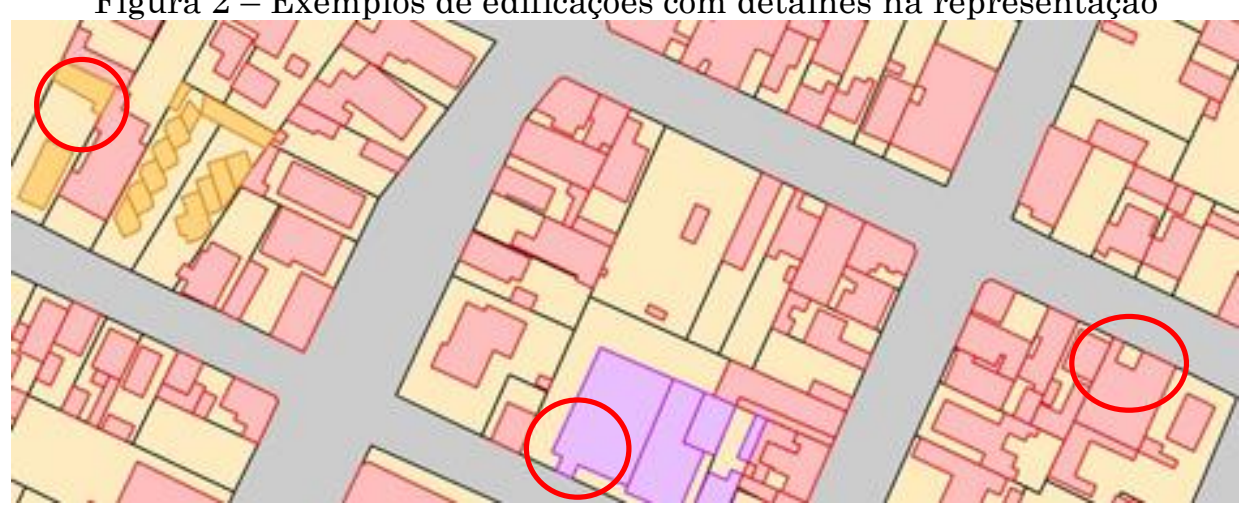

Fonte: Elaborada pelas autoras.

Foram apresentados aos participantes três quadrados igualmente espaçados entre si da mesma cor (Figura 3). Os valores de espaçamento avaliados são os mesmos independentemente da cor do símbolo. Para cada participante foi entregue um tipo de teste com polígonos (quadrados) de uma determinada cor. A SSC (2002) apresenta o valor de 0,20 $\mathrm{mm}$ para polígonos em tom cinza com contorno preto, o IGN da França sugere o valor de 0,15 mm para o mesmo tipo de símbolo. Os valores de espaçamento utilizados no teste foram: $0,10 \mathrm{~mm} ; 0,15 \mathrm{~mm} ; 0,25 \mathrm{~mm} ; 0,30 \mathrm{~mm} ; 0,40 \mathrm{~mm} ; 0,50 \mathrm{~mm}$ e 0,80 $\mathrm{mm}$. A Figura 3 ilustra as alternativas com espaçamento entre os polígonos de 0,80 $\mathrm{mm}$. Todos os polígonos têm lado igual a $1,5 \mathrm{~mm}$, independente da distância entre si.

Figura 3 - Símbolos avaliados para distância entre feições de área

\begin{tabular}{|c|c|c|c|}
\hline Tipo 1 & Tipo 2 & Tipo 2 & Tipo 4 \\
\hline$\square \square \square$ & $\square \square \square$ & $\square \square \square$ & $\square \square \square$ \\
\hline
\end{tabular}

Para avaliar a distância entre feições lineares e de área foi apresentado ao participante um quadrado e uma linha. O participante deveria assinalar as alternativas nas quais o espaçamento entre quadrado e linha era visível. A SSC (2002) apresenta o valor de 0,20 $\mathrm{mm}$ para distância entre quadrados e linhas na cor preta enquanto Taura (2007) propõe um valor de 0,25 mm para distância entre uma linha vermelha e um quadrado sem preenchimento com 
contorno vermelho. Os valores considerados nesse aspecto foram: $0,10 \mathrm{~mm}$; $0,20 \mathrm{~mm} ; 0,25 \mathrm{~mm} ; 0,30 \mathrm{~mm} ; 0,40 \mathrm{~mm} ; 0,50 \mathrm{~mm}$ e $0,70 \mathrm{~mm}$. Nas figuras abaixo todos os polígonos estão $0,70 \mathrm{~mm}$ distantes das linhas, independente das cores e tamanhos dessas figuras geométricas. Todos os polígonos têm lado igual $1,5 \mathrm{~mm}$ e as linhas têm $0,18 \mathrm{~mm}$ de espessura, conforme a simbologia proposta por Sluter et al. (2018).

Figura 4 - Símbolos avaliados para distância entre linha e polígono

\begin{tabular}{|c|c|c|c|}
\hline Tipo 1 & Tipo 2 & Tipo 3 & Tipo 4 \\
\hline$\square$ & $\square$ & $\square$ & $\square$ \\
$\square$ & $\square$ & $\square$ & $\square$ \\
$\square$ & $\underline{\square}$ & $\underline{\square}$ & $\underline{\square}$ \\
$\square$ & $\underline{\square}$ & $\underline{\square}$ & $\underline{\square}$ \\
\hline
\end{tabular}

Fonte: Elaborada pelas autoras.

\subsection{Caracterização dos Participantes}

Foram coletadas informações relativas à idade, gênero, experiência com cartografia para caracterização dos participantes. Também foram feitas perguntas relacionadas a problemas de visão. Caso usasse óculos ou lente de contatos, isto também deveria ser indicado, assim como a realização de cirurgias para correção de problemas de visão. Do total de 120 participantes que completaram o teste, 46 possuem problemas de visão, sendo que o problema citado por mais de $60 \%$ dos participantes foi a miopia.

Na Tabela 1 são apresentados os números referentes a quantidade de participantes que se identificam com os gêneros masculino ou feminino, a quantidade de participantes com problemas de visão e com experiência no uso de cartas topográfica, de acordo o tipo de teste apresentado ao participante. 
Tabela 1 - Quantitativo de usuários participantes do teste de percepção visual

\begin{tabular}{|c|c|c|c|c|c|c|}
\hline \multirow[b]{2}{*}{ Teste } & \multicolumn{2}{|c|}{ Gênero } & \multirow{2}{*}{$\begin{array}{c}\text { Problemas } \\
\text { de visão }\end{array}$} & \multicolumn{2}{|c|}{ Uso de cartas topográficas } & \multirow[b]{2}{*}{ Total } \\
\hline & Feminino & Masculino & & Experiência & $\begin{array}{c}\text { Sem } \\
\text { experiência }\end{array}$ & \\
\hline Tipo $1 \square$ & 15 & 14 & 21 & 23 & 6 & 29 \\
\hline Tipo $2 \square$ & 10 & 18 & 10 & 28 & - & 28 \\
\hline Tipo $3 \square$ & 10 & 20 & 12 & 29 & 1 & 30 \\
\hline Tipo $4 \square$ & 8 & 25 & 10 & 31 & 2 & 33 \\
\hline & & & & & & 120 \\
\hline
\end{tabular}

Fonte: Elaborada pelas autoras.

\section{RESULTADOS}

Os resultados dos testes de percepção visual são apresentados conforme a ordem de descrição na seção Questões do Teste de Percepção Visual. Para análise dos resultados foram construídos gráficos e tabelas com os quantitativos de cada aspecto avaliado. As dimensões mínimas consideradas legíveis foram determinadas com base nas porcentagens.

Com relação à distância entre três linhas paralelas, o resultado do teste indica que a distância mínima deve ser igual a $0,50 \mathrm{~mm}$ para que o usuário possa entender que há linhas paralelas na carta topográfica. O gráfico abaixo apresenta as alternativas (em milímetros) das questões pela porcentagem de participantes que assinalaram tais opções como legíveis. É possível observar que mais de $80 \%$ dos participantes assinalaram que com $0,50 \mathrm{~mm}, 0,70 \mathrm{~mm}$ e 1,00 $\mathrm{mm}$ de distância entre as linhas, pode-se ver claramente três linhas paralelas. Assim, conclui-se que a partir de 0,50 $\mathrm{mm}$ pode-se ver legivelmente a separação entre as três linhas.

Com relação à largura de um retângulo sólido, as três cores analisadas foram apresentadas a todos os participantes na mesma questão. O resultado do teste indica que a partir da largura de $0,50 \mathrm{~mm}$ para valores menores os usuários visualizam um retângulo como linha, ou seja, uma feição de área pode ser interpretada como uma feição linear. Para a simbologia correspondente a vias não pavimentadas, 91\% dos participantes indicaram que viram uma feição linear quando a largura do retângulo foi de $0,50 \mathrm{~mm}$. O 
valor é similar à simbologia para vias pavimentadas, em que $90 \%$ dos participantes assinalaram a largura de $0,50 \mathrm{~mm}$. Para a simbologia referente às rodovias, 84\% dos participantes assinalaram este valor. Estes números podem ser verificados na Tabela 2 . Os retângulos apresentados na Tabela 2 tem 2,00 mm de largura.

Figura 5 - Resultado do teste de percepção visual para linhas paralelas - Porcentagem de participantes x opções de espaçamento

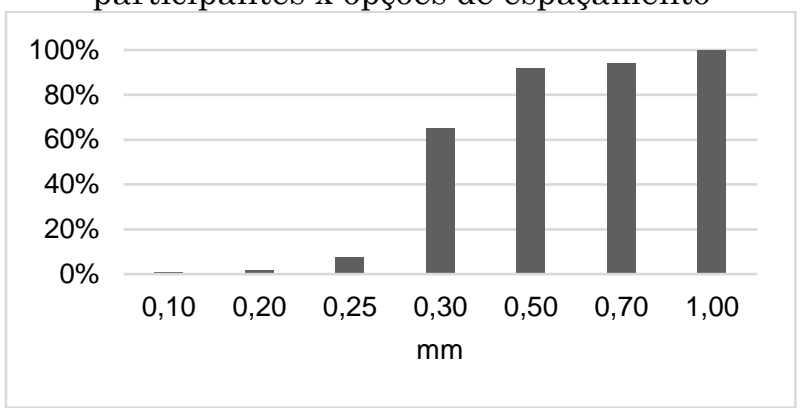

Fonte: Elaborada pelas autoras.

Tabela 2 - Resultado do teste de percepção visual para largura de um retângulo sólido Opções de largura e porcentagem de participantes

\begin{tabular}{c|c|c|c|c}
\hline \multirow{2}{*}{} & \multirow{2}{*}{ Questão 03 } & \multicolumn{3}{|c|}{ Porcentagem de participantes } \\
\cline { 3 - 5 } & $\mathrm{mm}$ & Rodovias & $\begin{array}{c}\text { Vias não } \\
\text { pavimentadas }\end{array}$ & Vias pavimentadas \\
\cline { 2 - 5 } & 0,30 & $100 \%$ & & \\
\hline a) & 0,50 & $84 \%$ & $100 \%$ & $100 \%$ \\
\hline b) & 0,80 & $59 \%$ & $90 \%$ & $91 \%$ \\
\hline c) & 1,00 & $33 \%$ & $63 \%$ & $59 \%$ \\
\hline d) & 1,20 & $23 \%$ & $34 \%$ & $38 \%$ \\
\hline e) & 1,50 & $11 \%$ & $26 \%$ & $28 \%$ \\
\hline f) & 2,00 & $6 \%$ & $14 \%$ & $15 \%$ \\
\hline g) & & $6 \%$ & $7 \%$ \\
\hline
\end{tabular}

Fonte: Elaborada pelas autoras.

Para o tamanho do lado de um quadrado sólido os resultados do teste apresentaram valores diversos, como mostram os gráficos da Figura 6. Três tipos de testes tiveram resultados similares, com mais de $80 \%$ de aceitação para o valor de 0,80 $\mathrm{mm}$. Para o teste Tipo 3, este mesmo valor de tamanho foi assinalado por 70\% dos participantes. Tais resultados e valores podem ser vistos na Figura 6. A SSC (2002) recomenda como dimensão mínima o valor 
de $0,80 \mathrm{~mm}$ para o lado de um quadrado com preenchimento de tom cinza com contorno. Deste modo, pode-se afirmar que a dimensão mínima do lado de um polígono colorido com contorno para esse ser legível é $0,80 \mathrm{~mm}$.

Figura 6 - Resultado do teste de percepção visual para lado de um quadrado sólido Porcentagem de participantes X opções de tamanho

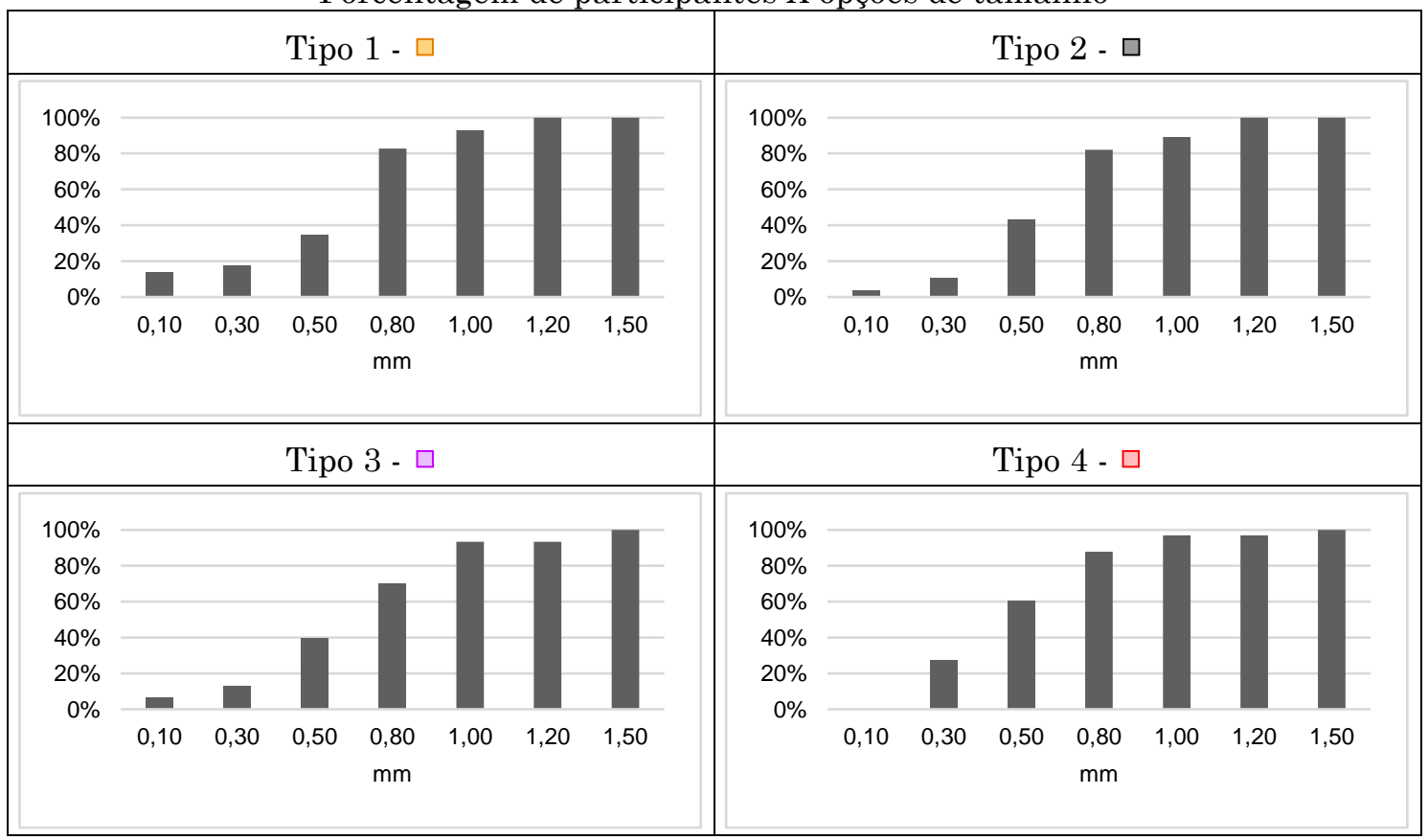

Fonte: Elaborada pelas autoras.

Para o lado de uma área interna de uma edificação os resultados também apresentam valores diversos entre os tipos de teste. Como é possível observar nos gráficos (Figura 7), para o teste Tipo 1 o valor mínimo assinalado por mais de $80 \%$ dos participantes foi de $0,60 \mathrm{~mm}$. Para o teste Tipo 2 o menor valor indicado por mais de $80 \%$ dos participantes foi de $0,50 \mathrm{~mm}$. Nas outras avaliações este valor é igual a $0,55 \mathrm{~mm}$. A SSC (2002) recomenda como dimensão mínima $0,40 \mathrm{~mm}$ para o lado de uma área interna de um quadrado sólido preto. Pode-se considerar que a partir de 0,55 $\mathrm{mm}$ de lado uma área interna de um polígono é legível.

Com relação ao tamanho do lado de detalhes de uma edificação, o resultado do teste de percepção visual aponta que a partir de $0,50 \mathrm{~mm} o$ usuário consegue visualizar o detalhe de uma edificação de modo legível. A 
SSC (2002) recomenda como dimensão mínima $0,25 \mathrm{~mm}$. O resultado do teste pode ser visto na Figura 8. Os detalhes existentes nos polígonos apresentados na Figura 8 tem lado igual a $1,00 \mathrm{~mm}$.

Figura 7 - Resultado do teste de percepção visual para o lado de uma área interna de uma edificação - Porcentagem de participantes X opções de tamanho

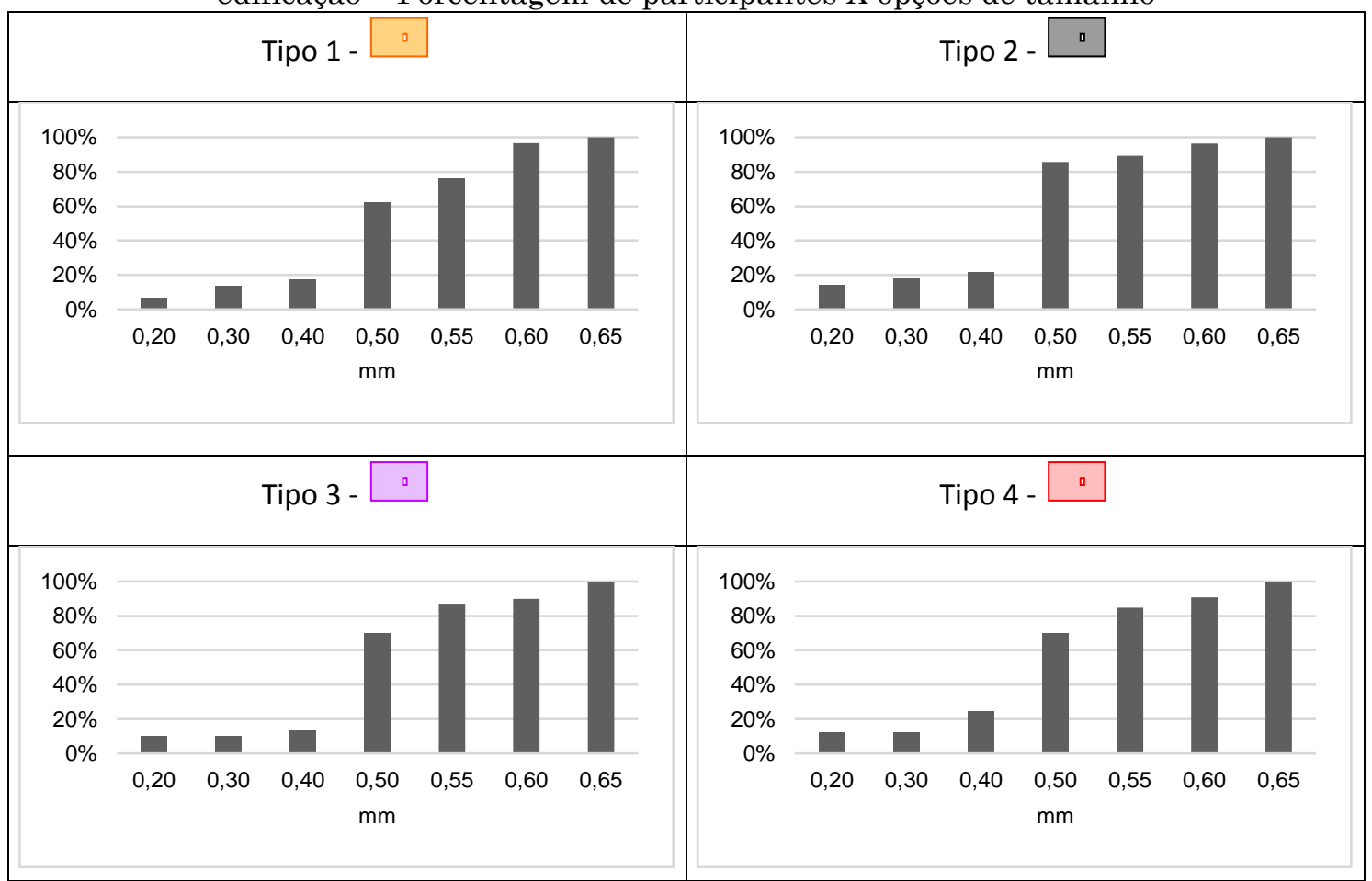

Fonte: Elaborada pelas autoras.

O resultado do teste para a distância entre polígonos indica que uma distância igual a $0,40 \mathrm{~mm}$ é suficiente para que o usuário possa visualizar claramente os polígonos e o espaço entre eles. A SSC (2002) não apresenta valor para este aspecto referente à polígonos coloridos. Os gráficos da Figura 9 apresentam os resultados conforme as cores avaliadas. 
Figura 8 - Resultado do teste de percepção visual para o lado de detalhes de uma edificação - Porcentagem de participantes X opções de tamanho

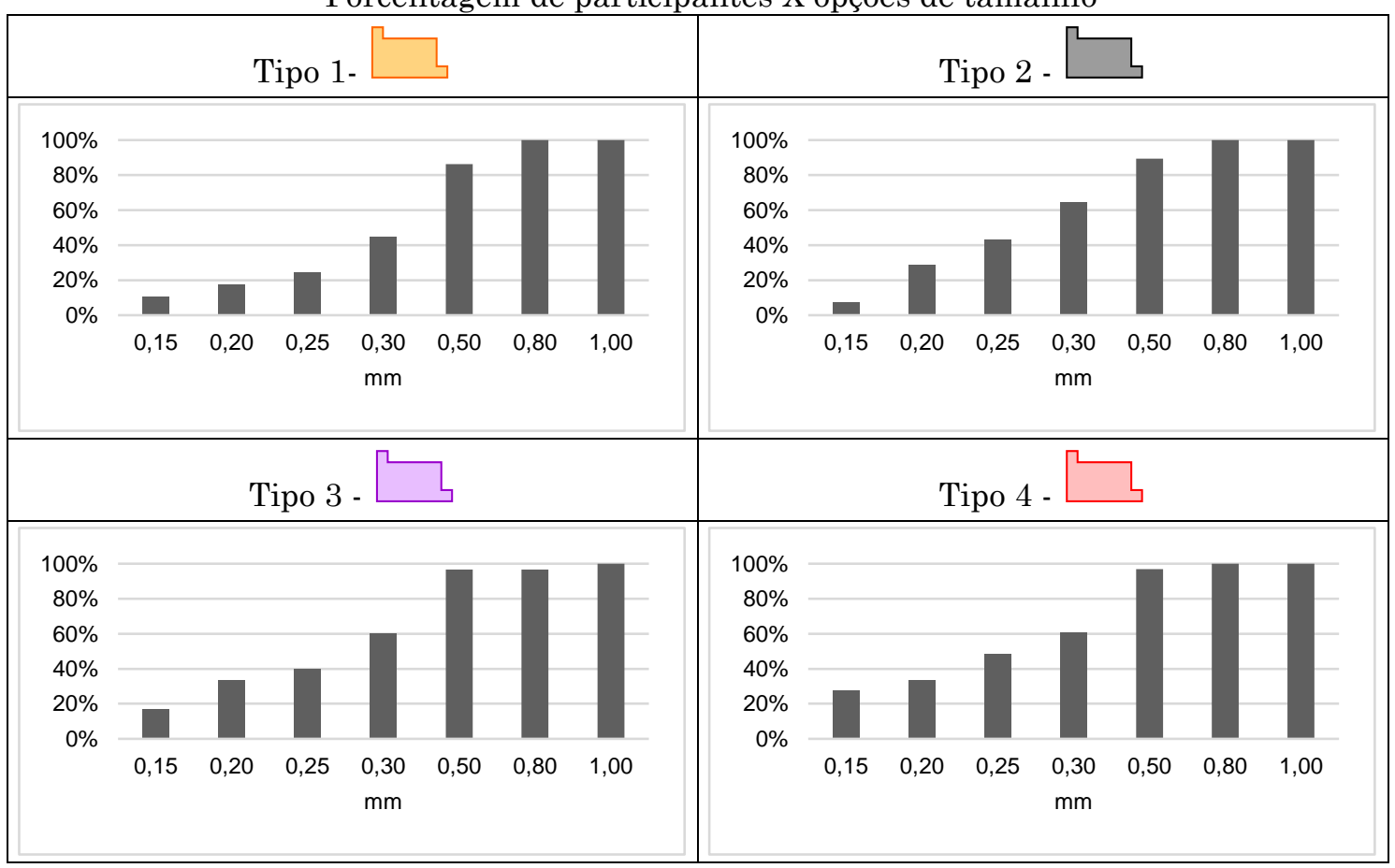

Fonte: Elaborada pelas autoras.

Figura 9 - Resultado do teste de percepção visual para a distância entre polígonos Porcentagem de participantes $\mathrm{X}$ opções de tamanho

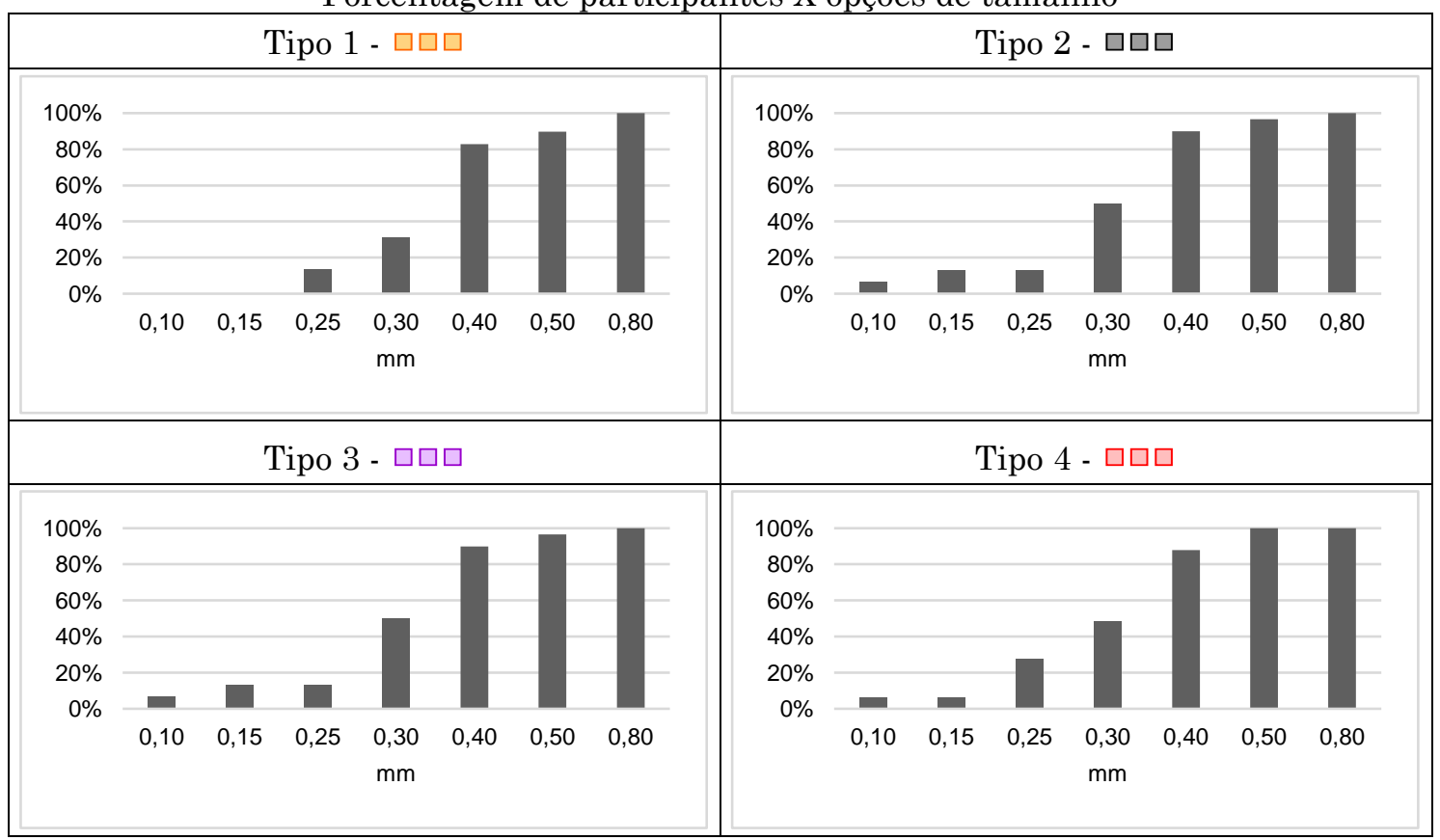

Fonte: Elaborada pelas autoras.

Com relação ao espaçamento entre feições lineares e feições de área, os resultados são diferentes para cada cor avaliada. A SSC (2002) recomenda um 
valor de 0,20 $\mathrm{mm}$, porém, para símbolos pretos representados em fundo branco. Para a apresentação dos resultados optou-se por comparar o resultado da distância entre a mesma cor de linha com polígonos de diferentes cores. A Tabela 3 apresenta o resultado do teste para as linhas referentes às vias pavimentadas. Para mais de $80 \%$ dos participantes, a partir de $0,40 \mathrm{~mm}$ a distância entre as feições é legível, para três dos quatro tipos de testes. Para a cor referente ao teste Tipo 3, pode-se considerar que a partir de 0,30 $\mathrm{mm}$ o usuário pode visualizar legivelmente a distância entre as feições.

Para a simbologia das vias não pavimentadas, pode-se afirmar que o usuário pode ver legivelmente a distância entre feições a partir de 0,50 mm, considerando três das quatros cores avaliadas. Para a cor referente ao teste Tipo 4, a menor distância entre as duas feições deve ser 0,40 mm para que o usuário possa ver a área e a linha de modo legível. Estes resultados são apresentados na Tabela 4 .

Tabela 3 - Resultado do teste de percepção visual de distância entre uma feição de área e uma feição linear - Ruas pavimentadas - Opções de distância e porcentagem de

\begin{tabular}{|c|c|c|c|c|c|}
\hline & & Tipo 1 & Tipo 2 & Tipo 2 & Tipo 4 \\
\hline & $\mathbf{m m}$ & $\square$ & $\square$ & $\square$ & $\square$ \\
\hline a) & 0,10 & $0 \%$ & $4 \%$ & $17 \%$ & $3 \%$ \\
\hline b) & 0,15 & $7 \%$ & $25 \%$ & $23 \%$ & $18 \%$ \\
\hline c) & 0,25 & $62 \%$ & $54 \%$ & $67 \%$ & $45 \%$ \\
\hline d) & 0,30 & $72 \%$ & $79 \%$ & $87 \%$ & $70 \%$ \\
\hline e) & 0,40 & $86 \%$ & $89 \%$ & $90 \%$ & $85 \%$ \\
\hline f) & 0,50 & $93 \%$ & $100 \%$ & $93 \%$ & $100 \%$ \\
\hline g) & 0,70 & $100 \%$ & $100 \%$ & $100 \%$ & $100 \%$ \\
\hline
\end{tabular}

Fonte: Elaborada pelas autoras.

Para linhas que representam os limites de propriedade também há diferenças entre os testes aplicados. $\mathrm{O}$ espaçamento mínimo de $0,30 \mathrm{~mm}$ é indicado por mais de $80 \%$ dos participantes para os polígonos com cores referentes aos testes Tipo 2 e Tipo 3 (Tabela 5). Este valor foi indicado como distância mínima por 76\% e 69\% dos participantes para as cores referentes aos testes Tipo 1 e Tipo 4. Para tais cores, o valor mínimo de distância para 
que o usuário possa ver legivelmente um grupo de polígonos deve ser igual ou maior que $0,40 \mathrm{~mm}$, valor apontado por $91 \%$ e $93 \%$ dos participantes, respectivamente.

Tabela 4 - Resultado do teste de percepção de distância entre uma feição de área e uma feição linear - Ruas não pavimentadas - Opções de distância e porcentagem de participantes

\begin{tabular}{c|c|c|c|c|c}
\hline & & Tipo 1 & Tipo 2 & Tipo 3 & Tipo 4 \\
\hline & $\mathbf{m m}$ & $\square$ & $\square$ & $\square$ & $\square$ \\
\hline a) & 0,10 & $0 \%$ & $4 \%$ & $10 \%$ & $3 \%$ \\
\hline b) & 0,15 & $0 \%$ & $7 \%$ & $10 \%$ & $9 \%$ \\
\hline c) & 0,25 & $34 \%$ & $32 \%$ & $37 \%$ & $42 \%$ \\
\hline d) & 0,30 & $62 \%$ & $50 \%$ & $53 \%$ & $67 \%$ \\
\hline e) & 0,40 & $76 \%$ & $71 \%$ & $77 \%$ & $82 \%$ \\
\hline f) & 0,50 & $93 \%$ & $93 \%$ & $87 \%$ & $91 \%$ \\
\hline g) & 0,70 & $100 \%$ & $100 \%$ & $100 \%$ & $100 \%$ \\
\hline
\end{tabular}

Fonte: Elaborada pelas autoras.

Para linhas referentes às rodovias, a distância mínima de $0,40 \mathrm{~mm}$ foi indicada por mais de $80 \%$ dos participantes para três tipos de testes. Para o teste Tipo 4, considera-se que a partir de $0,30 \mathrm{~mm}$ o espaçamento entre feições pode ser visto de modo legível. A Tabela 6 apresentam os resultados do teste para as linhas referentes às rodovias.

Tabela 5 - Resultado do teste de percepção visual de distância entre uma feição de área e uma feição linear - Limites de propriedade - Opções de distância e porcentagem de

\begin{tabular}{|c|c|c|c|c|c|}
\hline & & Tipo 1 & Tipo 2 & Tipo 3 & Tipo 4 \\
\hline & $\mathbf{m m}$ & $\square$ & $\square$ & $\square$ & $\square$ \\
\hline a) & 0,10 & $3 \%$ & $11 \%$ & $17 \%$ & $6 \%$ \\
\hline b) & 0,15 & $3 \%$ & $11 \%$ & $33 \%$ & $15 \%$ \\
\hline c) & 0,25 & $48 \%$ & $79 \%$ & $77 \%$ & $55 \%$ \\
\hline d) & 0,30 & $69 \%$ & $89 \%$ & $80 \%$ & $76 \%$ \\
\hline e) & 0,40 & $93 \%$ & $96 \%$ & $90 \%$ & $91 \%$ \\
\hline f) & 0,50 & $97 \%$ & $100 \%$ & $90 \%$ & $100 \%$ \\
\hline g) & 0,70 & $100 \%$ & $100 \%$ & $100 \%$ & $100 \%$ \\
\hline
\end{tabular}

Fonte: Elaborada pelas autoras. 
Tabela 6 - Resultado do teste de percepção visual de distância entre uma feição de área e uma feição linear - Rodovias - Opções de distância e porcentagem de participantes

\begin{tabular}{c|c|c|c|c|c}
\hline & & Tipo 1 & Tipo 2 & Tipo 3 & Tipo 4 \\
\hline & $\mathbf{m m}$ & $\underline{\square}$ & $\underline{\square}$ & $\underline{\square}$ & $\underline{\square}$ \\
\hline $\mathrm{a})$ & 0,10 & $3 \%$ & $7 \%$ & $17 \%$ & $6 \%$ \\
\hline $\mathrm{b})$ & 0,15 & $10 \%$ & $14 \%$ & $20 \%$ & $24 \%$ \\
\hline $\mathrm{c})$ & 0,25 & $62 \%$ & $46 \%$ & $63 \%$ & $64 \%$ \\
\hline $\mathrm{d})$ & 0,30 & $76 \%$ & $75 \%$ & $77 \%$ & $\mathbf{8 2 \%}$ \\
\hline $\mathrm{e})$ & 0,40 & $93 \%$ & $86 \%$ & $80 \%$ & $94 \%$ \\
\hline $\mathrm{f})$ & 0,50 & $97 \%$ & $93 \%$ & $87 \%$ & $100 \%$ \\
\hline $\mathrm{g})$ & 0,70 & $100 \%$ & $100 \%$ & $100 \%$ & $100 \%$ \\
\hline
\end{tabular}

Fonte: Elaborada pelas autoras.

Os resultados do teste de percepção visual não apresentaram discrepâncias quando se comparam os resultados obtidos pelo gênero masculino e pelo gênero feminino. Como exemplo disso, o gráfico abaixo apresenta o resultado do teste referente a distância entre linhas paralelas. É possível perceber que não há uma diferença notável entre as medidas de distâncias. A medida de $0,30 \mathrm{~mm}$ foi marcada por $60 \%$ das participantes do gênero feminino e por $68 \%$ dos participantes do gênero masculino. A menor medida assinalada como legível é igual a $0,50 \mathrm{~mm}$. No gráfico é possível notar que tal medida foi marcada por mais de $90 \%$ dos participantes, tanto do gênero feminino quanto masculino.

Figura 10 - Comparação do resultado do teste de percepção visual de linhas paralelas Gênero Feminino e Masculino

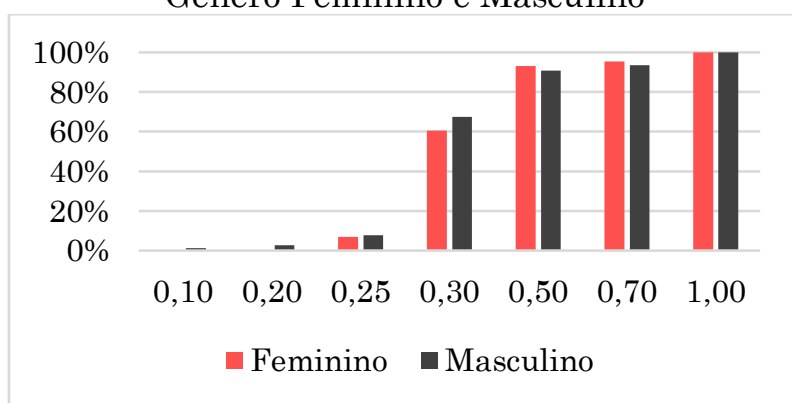

Fonte: Elaborado pelas autoras. 


\section{Discussão e recomendações}

O objetivo deste artigo foi a definição de critérios para o estabelecimento de dimensões mínimas para simbologia padrão utilizada nas cartas topográficas de escala grande do estado do Paraná. Este objetivo foi alcançado com os resultados obtidos com a aplicação de testes de percepção visual. Ressalta-se que as dimensões mínimas relacionadas aos tamanhos de símbolos e distância entre símbolos apresentaram valores diferentes para cores diferentes. Assim pode-se afirmar que as diferentes cores influenciam na percepção visual. A análise dos resultados ainda mostra que o gênero do participante não influencia na percepção visual.

Os resultados ainda confirmam dois aspectos verificados em outras pesquisas: (1) dimensões mínimas para simbologia colorida devem ser aumentadas consideravelmente, quando comparadas a símbolos pretos representados em fundo branco (SSC, 2002); (2) distância e tamanhos mínimos não são valores universais, quando considerados os limites de percepção visual (SAYIDOV e WEIBEL, 2016).

Como continuação desta pesquisa, sugere-se a aplicação deste teste com uma amostra maior do que a utilizada nesta pesquisa. Ainda se recomenda a elaboração das tarefas do teste da percepção visual que considere os símbolos no contexto de uso de cartas topográficas.

Com relação à simbologia proposta por Sluter et al (2018) ainda é necessário avaliar as dimensões mínimas dos símbolos pontuais para a indicação de instituições escolares, edificações de saúde e templos religiosos, visto que para tais classes as feições de área são representadas pela mesma simbologia.

A definição de dimensões mínimas é uma parte necessária para a aplicação da generalização cartográfica. Estes valores são utilizados para a automatização do processo, tanto na avaliação cartométrica para identificar problemas de representação quanto para avaliar o resultado do processo. A automatização desta etapa da generalização com o auxílio dos valores 
mínimos definidos nesta pesquisa pode minimizar o efeito da subjetividade deste processo.

\section{Contribuição dos autores}

Mônica Cristina de Castro, doutoranda responsável pela pesquisa, participou do planejamento, desenvolvimento, aplicação dos testes de percepção visual e coleta dos dados. Prof. Dra Claudia Robbi Sluter, orientou e supervisionou a pesquisa, o desenvolvimento e a análise dos resultados dos testes de percepção visual. As autoras participaram da redação do manuscrito, considerando etapas de leitura e revisão do texto.

\section{Referências}

BRASIL. Decreto Lei 243, de 28 de fevereiro de 1967. Fixa as Diretrizes e Bases da Cartografia Brasileira e dá outras providências, Brasília. Diário Oficial da União, 28 de fevereiro de 1967.

CAMBOIM, S.P; SLUTER, C.R. The National Topographic Mapping as Indispensable Database for a Brazilian National Spatial Data Infrastructure (NSDI). In: Proceedings of the $2^{\text {th }}$ International Cartographic Conference, Chile, 2009. pp 1-15.

CASTRO, M.C. Detecção da Ocorrência das Condições Geométricas no Processo de Generalização Cartográfica de Cartas Topográficas Urbanas com um Sistema Especialista. Dissertação de Mestrado. Universidade Federal do Paraná, Programa de Pós-Graduação em Ciências Geodésicas, Curitiba, 2014. 145p

COMÉ, S. Generalização Cartográfica para a Escala 1:10.000 das Feições Culturais de Áreas Urbanas Representadas em Cartas Topográficas na Escala 1:2.000. Dissertação de Mestrado. Universidade Federal do Paraná, Programa de Pós-Graduação em Ciências Geodésicas, Curitiba, 2014. 114p. 
COSTA RICA. Especificaciones Cartográficas para Mapa Topográfico Escala

1:25.000 de Costa Rica. Instituto Geográfico Nacional - Registro Nacional. 2016.

CTCG, Câmara Técnica de Cartografia e Geoprocessamento do Estado do Paraná.

Proposta de Convenções Cartográficas para o Mapeamento

Topográfico em Grande Escala no Estado do Paraná. Relatório Técnico, Grupo Padronização, Curitiba, 2009. 28p.

DSG, Diretoria Do Serviço Geográfico Do Exército. Manual Técnico T34-700

Convenções Cartográficas $2^{\mathrm{a}}$ Parte: Catálogo de Símbolos ( $2^{\mathrm{a}}$ edição), 2000.

FERNANDES, V.O. Análise das Cartas do Mapeamento Cadastral Urbano no Brasil: Proposta para Normatização da Simbologia. Dissertação de mestrado. Universidade Federal de Santa Catarina, Programa de PósGraduação em Engenharia Civil, Florianópolis, 2006. 472p.

MCMASTER, R.B; SHEA, K.S. A Comprehensive Conveptual Model. In: MCMASTER, R.B e SHEA, K.S. Generalization in Digital Cartography. Association of American Geographers, 1992. pp 27-69.

NALINI, V.T. Avaliação Cartométrica Da Base Cartográfica Digital Adequada à Gestão Urbana Derivada por Generalização Cartográfica a Partir da Escala de Origem 1:2.000. Dissertação de Mestrado. Universidade Federal do Paraná, Programa de Pós-Graduação em Ciências Geodésicas, Curitiba, 2005, 106p.

NATINGUE, G.R. Proposta de Simbologia para as Cartas na Escala 1:5.000 no Contexto de Mapeamento Topográfico do Estado do Paraná. Dissertação de Mestrado. Universidade Federal do Paraná, Programa de PósGraduação em Ciências Geodésicas, Curitiba, 2014, 130p.

PARANÁ. Plano Cartográfico do Estado do Paraná. Conselho de Cartografia do Estado do Paraná, Curitiba, 2010. 75p.

REGNAULD, N. Contextual Building Typification in Automated Map Generalization. Algorithmica, vol 30, 2001. pp 312-333.

SAYIDOV, A.; WEIBEL, R. Constraint-based Approach in Geological Map Generalization. Proceedings of $19^{\text {th }}$ ICA WorkShop on Generalisation and Multiple Representation, Finlandia, 2016. 
SSC, Swiss Society of Cartography. Map Graphics and Generalisation, Cartographic Publication Series No 17, Swiss Society of Cartography, 2002. $126 \mathrm{p}$.

SLUTER, C.R. Território. In: Brasil em Números, IBGE, Brasília, 2013, 45-52p.

SLUTER, C.R.; CAMBOIM, S.P.; IESCHECK, A.L.; PEREIRA, L.B.; CASTRO, M.C.; YAMADA, M.M.; ARAÚJO, V.S. A Proposal for Topographic Map Symbols for Large-Scale Maps of Urban Areas in Brazil. The Cartographic Journal, 55:4, 2018. pp 362-377.

TAURA, T. Estudo da Simbologia para Cartas nas Escalas 1: 2,000, 1:5,000 e 1:10,000 de Mapeamento Urbano do Paranacidade e Generalização Cartográfica. Dissertação de Mestrado, Universidade Federal do Paraná, Programa de Pós-Graduação em Ciências Geodésicas, Curitiba, 2007. 93p.

USGS, United States Geological Survey. Standards for 1:24,000 and 1:25,000 Scale Quadrangle Maps. National Mapping Program, Technical Instructions, Part 5, Publication Symbols, 1996. 